\title{
Un Nobel imperturbable
}

Rafael Conte

Traducteur : Roser Pardell

\section{OpenEdition}

Journals

Édition électronique

URL : http://journals.openedition.org/ccs/478

DOI : $10.4000 /$ ccs. 478

ISSN : 2558-782X

Éditeur :

Presses universitaires de Rennes, Association des lecteurs de Claude Simon

Édition imprimée

Date de publication : 31 décembre 2006

Pagination : 65-69

ISBN : 9782914518895

ISSN : $1774-9425$

\section{Référence électronique}

Rafael Conte, «Un Nobel imperturbable », Cahiers Claude Simon [En ligne], 2 | 2006, mis en ligne le 20 septembre 2017, consulté le 15 septembre 2020. URL : http://journals.openedition.org/ccs/478 


\section{Un Nobel imperturbable par Rafael CONTE}

En automne 1984, Claude Simon vint à Madrid pour prononcer, à l'Institut Français, une conférence d'une implacable beauté sur la description chez Balzac comme élément de base dans la genèse d'une nouvelle forme de récit. À cette occasion, j'eus avec lui un entretien, publié dans El Pais, car je trouvais curieuse cette revendication qu'il faisait de Balzac, lui, un insigne représentant de ce que nous appelions "Nouveau Roman " (alors que ce dernier se réclamait beaucoup plus de Flaubert), et qui constitue en fait la dernière avant-garde romanesque cohérente que le monde ait connue avant que le marché global n'en finisse avec toute tentative expérimentale. Jusques et y compris dans son propre pays, la guerre contre le "Nouveau Roman " a été brutale pendant plus d'un demi-siècle. Et la plus dure des accusations qu'on ait pu lui faire a été d'avoir détourné les lecteurs du roman, par sa dureté, sa rigueur expressive et le dogmatisme de ses positions.

Il se peut que les détracteurs du « Nouveau Roman » aient eu raison, mais les résultats ont été d'une telle pauvreté que les lettres françaises semblent avoir disparu du marché universel et du nôtre, en tout cas, presque totalement. Personne n'a jamais remplacé les grands représentants de ce mouvement ni dans leur pays ni dans aucun autre. Le règne du marché est maintenant total et, à la suite 
de ce cataclysme littéraire, l'œuvre de Claude Simon est pratiquement tombée dans l'oubli. Et pas même la mort de l'écrivain, survenue à quatre-vingt-onze ans, n'a pu modifier un état de choses où règnent les lois du marché et la dégénérescence culturelle.

Le prix Nobel qui fut décerné à Claude Simon un an après cette visite eut tout l'air d'être une rectification, si l'on en croit ce que Claude Simon m'avait dit au cours de l'entrevue citée ci-dessus (j'ai encore l'enregistrement). "Ils ne me donneront jamais le Nobel, m’avait-il confié amèrement. Les Suédois n'aiment pas les scandales. " Il faisait allusion à celui qu'avait provoqué un académicien suédois qui, en 1983, avait protesté parce qu’on avait donné le prix au britannique William Golding au lieu de le décerner à « un grand écrivain comme Claude Simon ». En l'occurrence, le scandale n'eut pas de fâcheuses conséquences.

En fait, le prix Nobel oscille beaucoup et se rectifie souvent luimême (par exemple le dernier décerné à Harold Pinter, l'a été pour répondre aux protestations faites l'année précédente lors de son attribution, jugée trop " féministe ", à la grande romancière autrichienne Elfriede Jelinek). Ainsi va l'histoire (si tant est que nous l'identifiions avec celle du prix Nobel, ce qui serait un abus), se démentant et se rectifiant sans cesse.

Cela dit, il est sage de rectifier et les résultats définitifs ne nous appartiennent pas. En fait cette année-là, le rival de Claude Simon n'était autre que son compagnon de mouvement et de génération, c'était - c'est encore, heureusement - Alain Robbe-Grillet, encore que, semble-t-il, les excès érotiques de son cinéma inquiétaient certains membres de l'académie suédoise " peu enclins aux scandales", comme me dit Claude Simon en 1984, ayant perdu tout espoir d'obtenir le prix qui lui fut pourtant décerné l'année suivante. En fin de compte, Robbe-Grillet est encore vivant et peut continuer à espérer même si la mode du " Nouveau Roman " a disparu de nos horizons culturels. Cependant, comme je pense que l'histoire ne passe jamais tout à fait et que ce qui fut ne cessera jamais d'être du moins pour ceux qui l'ont vécu (ou lu) - nous pouvons toujours continuer à rêver. 
Pendant ce temps, Claude Simon, aux manières discrètes et imperturbables, se présentait, dans ces années-là, comme un écrivain presque à la retraite, un campagnard habillé d'un blouson de cuir noir, un gentleman-farmer cultivant ses vignes depuis sa grande maison de Salses aux environs de Perpignan (ce qui rappelle William Faulkner, qu'il admirait, prix Nobel également, et qui, lors d'un voyage en France, se présentait comme " un fermier qui écrivait » et qui répondit à quelqu'un qui lui demandait les motifs de sa présence dans ce pays en disant que c'était parce que le Département d'État lui avait payé le voyage). Cela n'empêcha pas Claude Simon, discret, imperturbable comme toujours, de dire en privé au roi de Suède, au moment de recueillir son prix, que c'était la première fois que le descendant d'un maréchal de Napoléon (de la lignée de Bernadotte) remettait le prix au descendant d'un général du même Napoléon qu'était Claude Simon.

Claude Simon, mort à quatre-vingt-onze ans, était né à Tananarive (Madagascar) où avait été muté son père, militaire originaire du Jura, mort un an après à Verdun au début de la Grande Guerre. Claude Simon passa son enfance à Perpignan d'où était originaire sa pour ainsi dire aristocratique famille maternelle et dont les souvenirs sont rapportés dans ce petit joyau qu'est Le Tramway. Mais à la mort de sa mère, il fut élevé par un oncle à Paris où il fit ses études au collège Stanislas. Il veut être peintre - la fascination pour la peinture habite et explique toute son œuvre littéraire -, fréquente les milieux anarchistes, qui le conduiront à Barcelone où il milite dans les rangs républicains pendant les premiers jours de la guerre civile espagnole et dont les souvenirs lui inspireront un autre de ses romans, Le Palace. La déclaration de la Seconde Guerre mondiale le surprend alors qu'il est sous-officier de cavalerie dans les Flandres. Une déroute fulgurante s'ensuivit dont il allait témoigner dans sa première œuvre maîtresse, La Route des Flandres. Il fut fait prisonnier mais put s'évader, atteindre la zone « libre " au sud de son pays et lutter dans les rangs de la résistance contre les Allemands jusqu'au moment où, dans l'après-guerre, il se consacra entièrement à la littérature.

Ses quatre premiers romans - Le Tricheur, La Corde raide, Gulliver et Le Sacre du printemps - sont d'inspiration faulknérienne, 
les deux premiers figurent toujours comme étant "épuisés » dans ses bibliographies, et des deux suivants les premières versions espagnoles parurent au Venezuela. Jacobo Muchnik récupéra les deux suivantes en Argentine, L'Herbe et Le Vent, la première traduite par Miguel Angel Asturias et sa femme Blanca Mora de Araujo (les Nobel se touchent toujours). Entre-temps, Claude Simon avait été intégré par Jérôme Lindon, des "Éditions de Minuit ", dans l'opération "Nouveau Roman " comme un de ses piliers les plus importants, à côté de Nathalie Sarraute, Robbe-Grillet, Michel Butor, Claude Ollier, Robert Pinget, avec de plus Samuel Beckett ou, transitoirement, Marguerite Duras. Comme on peut le constater : rien de bien mauvais, puisqu'il y aurait là deux Nobel, un Goncourt, une Pléiade et trois survivants implacables. Finalement tout cela - la destruction du récit, la fragmentation du temps, la disparition des personnages - ne constituait pas un véritable groupe, mais plutôt une " association de malfaiteurs ", ainsi qu'ironisaient Sarraute et RobbeGrillet, puisque, en fait, chacun allait de son côté. Mais la parution en 2001 de La Reprise de Robbe-Grillet et du Tramway de Claude Simon a ramené ces écrivains dans l'actualité et a secoué les milieux littéraires de leur pays. À l'évidence, le « Nouveau Roman » est un cadavre qui jouit d'une assez bonne santé, quoi qu'on en dise.

Toute l'œuvre de Claude Simon vient de la peinture, de la manière de voir un tableau, de loin ou de près, depuis les ensembles clairs et lointains jusqu'aux plus inextricables et minuscules touches de pinceau, et où on utilise la description pour tout torpiller - et ainsi tout renouveler - dans une incessante allée et venue entre le temps et l'histoire. À l'influx faulknérien s'est ajouté celui de Marcel Proust, et l'utilisation écrasante et massive du descriptivisme d'un Balzac comme "bulldozer ». La peinture nous offre - en nous approchant à chaque touche comme avec un microscope - la complexité du réel comme vue par un télescope. Tout est morceaux, fragments, segments, mélanges, combinaisons, introductions dans le tissu narratif de trames toujours existantes par-dessous, mais qu'il faut poursuivre jusqu'à l'exaspération. Entre le temps et l'histoire s'est introduite la mémoire avec ses allées et venues continuelles qui secrètent ce que nous appelons littérature, laquelle, à son tour, est reconstruite en permanentes ruines par la magistrale et toujours 
apocalyptique vision de l'écrivain. Et nous allons ainsi de l'autobiographique à l'historique, d'une guerre à l'autre, des souvenirs d'enfance à ceux de sa famille, des clés métalittéraires de La Bataille de Pharsale - ou « de la phrase» - à Triptyque, Les Corps conducteurs ou Leçons de choses pour culminer avec ces reconstructions que sont Les Géorgiques, L'Acacia et Le Jardin des Plantes, son avant-dernier " portrait d'une mémoire ", ses œuvres maîtresses finales.

Le Tramway n'est pas aussi grand, c'est une ouvre plus petite, mais tout ce qu'a fait Claude Simon est gigantesque si nous regardons tout autour. Un tramway va - allait dans les années vingt - du centre de Perpignan à une plage proche, transportant des enfants, des écoliers, des ouvriers, des estivants, des bourgeois, dans lesquels se vident les souvenirs du temps disparu, cependant que la voix d'un vieillard s'auto-scrute dans son lit d'hôpital où il vient d'être opéré. Et, de manière moins chaotique et plus transparente qu'il n'y paraît, les images s'égrènent l'une après l'autre, depuis la caricature d'un autre vieux malade jusqu'à la mort de la mère ou celle, inoubliable, de la servante qui grille des rats sur les fourneaux, tout s'entretisse comme en un mausolée génial, tout circule, dans notre intérieur, en une succession d'images impérissables. Rappelons que la valeur d'un bijou ne se mesure pas à sa taille. Inoubliable.

Traduit de l'espagnol par Roser Pardell 